\title{
Categorization of building product models in BIM Content Library portals
}

\author{
> Kereshmeh Afsari \\ Georgia Institute of Technology, USA \\ kafsari3@gatech.edu
}

\author{
> Chuck Eastman \\ Georgia Institute of Technology, USA \\ chuck.eastman@arch.gatech.edu
}

\begin{abstract}
BIM Content Libraries are performing as online sources for building product models. In order to effectively use the product models, it is important to organize them systematically within these databases. But currently there is no standard or guideline for this purpose. Products in these libraries are being categorized based on different criteria such as the object classes in the target platform, by referring to multiple classification systems or based on customized categories. This paper studies some of the BIM Content Libraries and investigates the structure that each library is using for product categorization. It indicates the need for a generic framework for the purpose of product categorization in BIM Content Libraries.
\end{abstract}

Keywords: BIM objects; Product models; Building models; BIM Content Library; Product category

\section{Introduction}

There is a large number of building product manufacturers worldwide and each manufacturer produces a few and sometimes thousands of products (Eastman et. al, 2011). As the adoption of Building Information Modelling (BIM) grows, designers and contractors will require model-based, BIM-ready information from building product manufacturers and fabricators (Autodesk, 2013) to integrate the data into the building model. Building product models or also known as Building Object Models are basically Building Information Model components with 2D and 3D geometric representations. They are representing physical products such as doors, windows, equipment, furniture and electrical or plumbing fixtures. These objects also include high-level assemblies of walls, roofs, ceilings and floors (Eastman et. al, 2011) and also assemblies of furniture systems or space equipment layout. In other words, they include basic objects that are needed to define a building as a physical entity (Keijer, 1993).

BIM authoring tools provide a built-in library of categorized components that include geometry as well as nongraphic attributes (Rundell, 2008). In addition to these built-in libraries of components, building product libraries, as we call them "BIM Content Libraries", are web portals for building product models where the user can navigate, search and download BIM contents (Eastman et. al, 2011). These online sources are databases for building product models to support reusability of products' information (Autodesk, 2011).

It should be noted that, previously, the term "Building Product Modeling" (Eastman, 1999) was used to describe what is currently known as "Building Information Modeling". The term "Building Product Model" was also used when referring to the project's model describing a particular building. But in this paper, we use the term "Building Model" which is also known as Building Information Model to refer to the project's model that represents the building. By "Building Product Models" or simply "Product Models" we mean products or objects that are the components of the building model.

\section{Generic vs. Proprietary Product Models}

Within the BIM Content Libraries there are generally two major groups of product models based on the various levels of detail needed in the building models. First group is generic product models that are provided mainly to be used at the early stages of the design process where manufacturer specific data is not needed. Generic objects rarely require very high levels of detail (Mordue, 2012).

As well as generic product models, building product manufacturers have been providing the $3 \mathrm{D}$ models of their products that are BIM enabled. This way, they can make sure that their products are part of the project during the design process. These BIM-ready models are data-rich and contain the information designers and contractors need but they should not be overloaded with unnecessary information (IMAGINiT, 2011). As the building model develops and a project progresses, the conceptual generic product models will be replaced by detailed objects and further, these will be replaced by manufacturers' or proprietary product models (Mordue, 2012) and later on during the construction and facility management phase, actual products will take over in the building. 
Creating libraries of manufacturer's specific product models is time consuming and practically it is not efficient to develop multiple manufacturers' product models within design firms. That is in fact the main driver for the development of BIM Content Libraries specifically since they can perform as an online marketing source for product manufacturers too. These models can also be considered as product catalogs (Autodesk, 2011). For that reason, development of proprietary product models in BIM Content Libraries is paid for by product manufacturers and therefore, users can download these models for free. There are also some instances (e.g. Hilti) that the development and distribution of building product models are done by manufacturers directly from their own website (Rundell, 2008).

\section{Organization of BIM Content Libraries}

BIM Content Libraries contain a lot of BIM related information for a range of product models that can be used in some BIM applications. However, due to the variety of building products and because of the large number of objects and assemblies new challenges arise in developing and managing BIM Content Libraries (Eastman et. al, 2011). Product models are being shared through these portals and being integrated within the building models both nationally and internationally in several stages of the project. In order to understand and effectively use product models, it is critical to organize them systematically in these libraries. Keijer (1993) and Howard (2001) indicate the need for a common language for organizing information when it comes to the building information and IT system requirements (Howard, 2001; Keijer, 1993). On the other hand, Ekholm (1999) believes that it is important to consider how these databases are being structured for the purpose of product documentation (Ekholm, 1999). The main purpose of documenting product models in BIM Content Libraries is to integrate the library models into the building models. The major aspect in this integration involves the translation of objects to the standard structure and nomenclature that is defined within the target applications (Eastman et. al, 2011). In order to fully integrate the objects into the building models five aspects are critical: object class, object reference to the classification systems, naming conventions, attribute structure and Interfaces with other objects (Eastman et. al, 2011). The first two aspects which are the object classes and references to the building classification systems are affecting the organization of BIM Content Libraries in terms of categorization of the products.

In other words, in order to organize thousands of building product models in BIM Content Libraries they need to be grouped into proper categories. This will provide a quick access to the building product models of the same category. In categorization of products three criteria can be used:

a. Object classes that are defined in the target platform

b. Using references to the classification systems

c. Customized categorization system

Object classes in the target platform

BIM authoring tools (e.g. Autodesk Revit, Graphisoft ArchiCAD, Bentley AECOsim Building Designer, etc.) have each defined their own object classes such as wall, column, beam, etc. So, in order to integrate the objects into the building model, predefined object classes in the target application needs to be considered. Accordingly, this grouping strategy can be used to organize BIM Content Libraries. That means objects under one category in BIM Content Libraries can have the same object class in the target application. This might get complicated when it comes to the products that consist of nested objects and assemblies of products.

\section{Reference to the classification systems}

Classification codes are useful indices for grouping building products and organizing BIM databases (Eastman et. al, 2011). By giving the proper classification code to building product models, they can be arranged for construction information, cost estimation and also they can be sorted within the databases. However, when dealing with the classification systems, it is necessary to consider the purpose of the classification (Ekholm, 1996; Ekholm \& Häggström, 2011; Jørgensen, 2011). Based on the purpose of each classification, the properties of interest are distinguished in that system. Therefore the objects are sorted into classes with regard to the chosen properties (Ekholm A. , 1996). So, if one classification system is used for grouping product models in BIM Content Libraries, the purpose behind that classification system will define the product categorization theme within the library. For that reason, the purpose of the library categorization should be defined before choosing the target classification system. For instance, one purpose of grouping building product models could be dealing with the product specifications. So, for this purpose classification systems that are produced for organizing information about product specification (e.g. MasterFormat from North America) can be used for library categorization.

\section{Customized categorization systems}

These two strategies (object classes in the target platform and references to the classification systems) can be used separately or together to categorize BIM Content Libraries. Also, customized categories can be derived and adopted for a specific purpose. These customized grouping should be semantically organized. One example could be the use of customized category as "bench" instead of using the "furniture" object class if referring to the target application classes. These categories can also be opted based on the availability of the products on the database or the demand for a particular set of products. For instance, if there are a large number of benches in a BIM Content Library or there is a specific demand for it, that might be needed to have a separate category for that. This categorization strategy does not follow any standardized vocabularies or terminology but it should follow some human-readable semantics and it might have a hierarchy of categories.

\section{Product Categorization in BIM Content Libraries}

Some examples of BIM Content Library portals are Autodesk Seek, Arcat, SmartBIM, the UK's NBS BIM library and BIMcomponents. These libraries are among the most widely used public portals. They are selected in this study for investigating different strategies that 


\begin{tabular}{|c|c|c|c|c|c|}
\hline $\begin{array}{l}\text { BIM Content Library } \\
\text { Portals }\end{array}$ & Autodesk SEEK & SmartBIM & BIMComponents & ARCAT & $\begin{array}{l}\text { UK NBS National BIM } \\
\text { Library }\end{array}$ \\
\hline $\begin{array}{l}\text { Generic product } \\
\text { models }\end{array}$ & Yes & Yes & Yes & Yes & Yes \\
\hline $\begin{array}{l}\text { Manufacturer specific } \\
\text { product models }\end{array}$ & Yes & Yes & Limited & Yes & Yes \\
\hline $\begin{array}{l}\text { Supported formats/ } \\
\text { Target platforms }\end{array}$ & $\begin{array}{l}\text { Autodesk Revit and } \\
\text { AutoCAD }\end{array}$ & $\begin{array}{l}\text { Autodesk Revit and } \\
\text { AutoCAD }\end{array}$ & ArchiCAD & $\begin{array}{l}\text { Autodesk Revit, } \\
\text { AutoCAD, DGN } \\
\text { Bentley Architecture/ } \\
\text { AECOsim }\end{array}$ & $\begin{array}{l}\text { Autodesk Revit, ArchiCAD, } \\
\text { AECOsim, Vectorworks, } \\
\text { IFC }\end{array}$ \\
\hline $\begin{array}{l}\text { Categorization based } \\
\text { on object classes in } \\
\text { target applications }\end{array}$ & - & $\begin{array}{l}\text { Based on Revit object } \\
\text { classes ( } 23 \text { categories) in } \\
\text { alphabetical order }\end{array}$ & - & - & - \\
\hline $\begin{array}{l}\text { Categorization based } \\
\text { on reference to } \\
\text { the classification } \\
\text { systems }\end{array}$ & $\begin{array}{l}\text { Three classification } \\
\text { systems hierarchy: } \\
\text { OmniClass } 1.0 \text {, } \\
\text { UniFormat II, } \\
\text { MasterFormat } 2004\end{array}$ & - & - & $\begin{array}{l}\text { Categories based on } \\
\text { MasterFormat } 2014 \\
\text { divisions }\end{array}$ & $\begin{array}{l}\text { Categories based on Uniclass } \\
2 \text { in alphabetical order }\end{array}$ \\
\hline $\begin{array}{l}\text { Customized product } \\
\text { categorization }\end{array}$ & $\begin{array}{l}\text { Customized categories } \\
\text { in six main groups/tabs }\end{array}$ & - & $\begin{array}{l}\text { Customized categories } \\
\text { mixed with ArchiCAD } \\
\text { object classes, in } \\
\text { alphabetical order } \\
\text { with word cloud } \\
\text { representation }\end{array}$ & $\begin{array}{l}\text { Customized } \\
\text { categories ( } 23 \\
\text { categories) in } \\
\text { alphabetical order }\end{array}$ & - \\
\hline
\end{tabular}

Table I: BIM Content Libraries and product model categorization strategies

are being used for building product model categorization. The study of the categorization systems that these portals have opted for the organization of their databases is summarized in Table 1.

Autodesk Seek (http://seek.autodesk.com) uses a customized high-level grouping with customized categories. They currently group their 38 categories under 6 main groups: building, electrical, site, mechanical, interior and plumbing and piping. Although their target BIM platform is Autodesk Revit, their recent product categories does not follow the object classes in Revit. They have some customized categories like garage doors, sofas and faucets that don't have a separate class within Revit. In addition to this customized categorization, they offer their product categories under three classification systems OmniClass, MasterFormat and UniFormat. But currently the versions of OmniClass and MasterFormat being used for Autodesk Seek product classification are not the latest. It supports both generic and proprietary product models.

Arcat (www.arcat.com) has a library of building products that are categorized in two ways. First strategy that this portal is using is with regard to the product specification and is based on MasterFormat, so, the object classes follow the latest (2014 revision) MasterFormat divisions. Second strategy that it uses is a customized categorization system that is somehow similar to MasterFormat divisions but more intuitive and includes 23 product categories ordered alphabetically and are represented by tabs. Arcat mostly provides proprietary product models but in some cases also offer generic product models.
SmartBIM library (http://library.smartbim.com) currently categorizes its Building product models based on the object classes in Autodesk Revit since this is currently its target platform. It orders products in 23 categories that each represents a separate object class in Revit. It arranges them in an alphabetical order represented in tabs. SmartBIM library also provides categorization based on the object type and manufacturers list and it has both generic and manufacturer specific product models but it currently does not categorize the product models under any classification system.

The UK's NBS National BIM library (www.nationalbimlibrary. com) categorizes building product models both under the object types and manufacturer's list providing both generic and proprietary product models. For the object categories, NBS library is classified using Uniclass 2 (Hamil, 2013) which is the UK's building classification system. It uses the classes in Uniclass 2 product table but in some instances it has simplified the naming of the classes. Although this library is referring to Uniclass 2, for representing the product classes it organizes the categories in an alphabetical order and not based on the order and numbering in Uniclass 2. They support a range of formats and have targeted several applications like Autodesk Revit, ArchiCAD, AECOsim and Vectorworks. They also provide the IFC file of most of their building product models.

BIMcomponents (https://bimcomponents.com) provides BIM objects for ArchiCAD users. Graphisoft's BIM library categorizes building product models in a customized way that is slightly similar to the object classes in ArchiCAD but it is in 59 categories. They are ordered alphabetically and represented with a word cloud system on 
the first page of the portal. It provides mostly generic products and currently some very limited manufacturer specific product models.

\section{Discussion}

Each of the selected BIM Content Libraries has their own way of organizing product model databases which is different from the others. Although they are storing similar sets of product models, their data access organizations are different for several reasons. First and foremost the framework that each uses for the categorization is different. For instance, SmartBIM is using object classes within Revit (which is their target platform) to organize their product models and NBS BIM library uses classification systems (Uniclass 2) for its product categorization and it has several target platforms. Here we revisit three product categorization criteria that we mentioned earlier with reference to the examples of BIM Content Libraries to discuss how these criteria are different.

a. Object classes in target platform: BIM platforms have each defined and implemented a set of object classes, using their own component structure and naming conventions. This is based on the concept used in their data structure. In order to support the integration of the product models into the building models, some BIM Content Libraries like SmartBIM consider the standards and structure of the target platform for organizing the database and this can be different in each target platform. Therefore, although this categorization system might be easier to use for the users who are familiar with the target platform, it does not conform to any general or standard convention and will be different for the databases with different target platforms. This will cause problems when comparing same products in multiple libraries. In addition, object classes sometimes are more generic than the actual range of products they include. For example, in Autodesk Revit, "furniture" class includes all classes of furniture such as chair, desk and bench that each might need a separate category to represent related products. This leads to the question that what could be the criteria for "sub-category" definition. Because subcategories do not follow the "object class" notion in target platforms, they should be defined based on a customized categorization that has its own challenges discussed later.

b. Reference to the classification systems: Some library portals have developed their categories based on the classification systems such as Arcat using Masterformat divisions and NBS library referring to Uniclass 2. Some libraries, like Autodesk Seek provide optional product categorizations based on the classification codes in various systems such as Omniclass, UniFormat and MasterFormat. This way, for the user who is familiar with standard classifications, it would be easier to find products of a specific class. While referring to the classification systems supports a common standard terminology, it introduces challenges for organizing BIM Content Libraries. There is a variety of classification systems developed by different countries such as BSAB in Sweden, DBK in Denmark, Uniclass in the UK, Building 90 in Finland and OmniClass in North America (Jørgensen, 2011) and each has their own way of classifying construction artifacts (Ekholm \& Häggström, 2011). As mentioned earlier, when referring to the classification systems, the purpose of the classification defines its grouping criteria. The fact is that there is no specific classification system that is developed for the purpose of building product categorization within BIM Content Libraries. Some classifications however, are developed for the purpose of classifying product models in the building models such as OmniClass Table 23. But in dealing with building products, specification is also another important aspect and for this purpose some other classification systems like MasterFormat need to be referred. For that reason, this causes inconsistencies in comparing similar products in multiple libraries that are referring to different classification systems. Also, object classes in the classification systems sometimes are not very intuitive or may use long terminologies while simple keywords are needed for grouping of products. One example in this regard is "Adhesives and bonding compounds" class in Uniclass 2 that is too long and is summarized to "Adhesives" on NBS BIM library. Also, in MasterFormat 2014 division 34 which is "Transportation" has "Yard Management Equipment" as sub-class, so such equipment are grouped under "Transportation" category that might not be easily comprehensible. Ordering of the object classes with referring to the classification systems is also another challenge in BIM Content Libraries since classifications deal with a large number of classes with specific numbering structures. For that reason some libraries such as NBS BIM library have chosen to use alphabetical ordering instead.

c. Customized categorization: This grouping strategy can be more intuitive and therefore much easier to use. However, because it is not following any established framework, the structure of grouping and vocabulary can differ from library to library. In other words, this does not support a common approach that is based on agreed terminologies. This makes it difficult to find or compare similar categories of products in multiple libraries that are organized using customized classes of products.

\section{Conclusion}

BIM library portals need to group their product models based on limited categories and sub-categories of products to provide a quick access to the building product models of the same category. Currently there is no clear guideline or documentation on the idea of how to organize building product models within BIM Content Libraries. A generic framework would help adhere to a common language for a well-designed structure. Using an open BIM standard such as Industry Foundation Classes (IFC) might be an option for this purpose. IFC architecture includes a series of object classes that can be used as a classification system itself. IFC theoretically could be helpful for this purpose but currently it cannot fully support product categorization because it does not include some of the object classes within the building models such as planting.

In brief, a framework is required for the purpose of building product categorization in BIM Content Libraries.

\section{Future work}

The need for a framework for building product categorization in BIM Content Libraries has identified in this paper. In order to develop the framework, it is required to do a study on product categories as a systematic conceptualization of the domain 
knowledge that is known as ontology (Gursel et. al, 2009; Beetz et. al, 2008). This should also integrate buildingSMART Data Dictionary (bSDD) also known as IFD library that is an ISO 12006-3 based ontology for the building and construction industry (buildingSMART, 2014).

Clearly, the framework should incorporate multiple facets (e.g. classification, ontology, object classes in building models) that can come up with a product categorization strategy that is semantically relevant. This is basically an intermediate layer for organizing BIM Content Libraries that provides:

- Mapping to classification systems that refer to the building product model classes in the building models as well as to the product specifications.

- Mapping guidelines to the object classes in the native building model as well as IFC schema.

- Reference to the buildingSMART Data Dictionary (bSDD)

Future study could develop an expanded form of Omniclass tables combining multiple related tables such as table 21, 22 and 23. This could be developed as a multi-key DBMS by setting up an access structure that provides retrieval through a combination of key attributes (Elmasri and Navathe, 2010) allowing multiple types of queries such as queries based on the product function in the building or based on the product specification or even based on a certain combination of key attributes. It needs to be intuitive with easily understood standard terminology.

\section{Study limitations}

BIM Content Library portals change over time due to the changes of the products, changes of the classification systems and revisions of the customized product categories being used. Products and service categories also undergo continuous changes due to innovation. Therefore, this study is limited to the status of the portals that are studied above, during August and September 2014.

\section{References}

Autodesk. (2011). Autodesk Seek. Autodesk.

Autodesk. (2013). Building Products, Equipment \& Fabrication. Retrieved Nov 2013, from Autodesk: http://www.autodesk. $\mathrm{com} /$ industry/product-design-manufacturing/building-products-equipment-fabrication

Beetz, J., van Leeuwen, J., and de Vries, B., (2008), IfcOWL: A case of transforming EXPRESS schemas into ontologies, Artificial Intelligence for Engineering Design, Analysis and Manufacturing, 23:89-101

buildingSMART. (2014). BuildingSMART Data Dictionary (bSDD). Retrieved Sep 2014 from buildingSMART: http:// www.buildingsmart.org/standards/ifd

Eastman, C, (1999). Building Product Models: Computer Environments Supporting Design and Construction, CRC Press, Inc. Boca Raton, FL, USA.

Eastman, C., Teicholz, P., Sacks, R., \& Liston, K. (2011). BIM handbook: A Guide to Building Information Modeling for
Owners, Managers, Designers, Engineers and Contractors, Chapter 5, (pp.240-253). Wiley.

Elmasri, R., \& Navathe, S. (2010). Fundamentals of database systems, sixth edition, Chapter 14, (pp.540-545). Boston, Pearson/Addison Wesley.

Ekholm , A. (1999). Co-ordination of classifications for product modelling and established building. Proceedings of CIB W78 Workshop at the $8 \mathrm{dbmc}$ conference. Vancouver, Canada; May 30-June3: NRC Research Press. Retrieved Sep 2014 from http://www.lth.se/fileadmin/projekteringsmetodik/research/ Construction_informatics/Ekholm_W78_99.pdf

Ekholm, A. (1996). A conceptual framework for classification of construction works. ITcon (Electronic Journal of Information Technology in Construction) Vol.1, p.1-25.

Ekholm, A., \& Häggström, L. (2011). Building classification for BIM - Reconsidering the framework. Proceedings of the CIB W078-W102: 2011 Joint International Conference. Sophia Antipolis, France; 26-28 October. Retrieved Sep 2014 from http://2011-cibw078-w102.cstb.fr/papers/Paper-20.pdf

Gursel, I.k, Sariyildiz, S., Stouffs, R.i, Akin, Ö. (2009) Tidafi, T. and Dorta, T. (eds) Contextual Ontology Support as External Knowledge Representation for Building Information Modeling, Joining Languages, Cultures and Visions: CAADFutures 2009, pp 487-500.

Hamil, S. (2013, Feb). The benefits of using a structured approach to data. Retrieved Sep 2014 from NBS: http://www.thenbs. com/topics/DesignSpecification/articles/benefitsOfStructuredApproachData.asp

Howard, R. (2001). Classification of building information- European and IT systems. In B. F. Coetzee G (Ed.), Proceedings of IT in construction in Africa. Mpumalunga, South Africa ; 30 May - 1 June. Retrieved Sep 2014 from ITC Digital Library: http:/itc.scix.net/data/works/att/w78-2001-12.content.pdf

IMAGINiT. (2011). BIM for Manufacturers. Retrieved Sep 2014, from IMAGINiT: http://www.imaginit.com/services/consulting-services/bim-for-manufacturers

Jørgensen, K. A. (2011). Classification of building object typesMisconceptions, challenges and opportunities. Proceedings of CIB W78-W102 International Conference. Sophia Antipolis, France; 26-28 October. Retrieved Sep 2014 from http://2011cibw078-w102.cstb.fr/papers/Paper-24.pdf

Keijer, U. (1993). Building integrity: Classification beyond building parts and spaces. In K. Mathur, M. Betts, \& K. Tham (Ed.), Management of information technology for construction. Singapore: August 1993.

Mordue, S. (2012, Jul). National BIM Library generic content release 2. Retrieved Sep 2014 from NBS: http://www.thenbs. $\mathrm{com} /$ topics/bim/articles/nblgenericcontentrelease2.asp

Rundell, R. (2008, Jan 1). BIM and Building Product Manufacturers. Retrieved Sep 2014, from cadalyst: http://www.cadalyst. com/aec/bim-and-building-product-manufacturers-1-2-3-revit-tutorial-3699 